\title{
MANEJO DE Conyza bonariensis RESISTENTE AO HERBICIDA GLYPHOSATE $^{1}$
}

\author{
Management of Glyphosate-Resistant Conyza bonariensis
}

PAULA, J.M. ${ }^{2}$, VARGAS, L. ${ }^{3}$, AGOSTINETTO, D. ${ }^{4}$ e NOHATTO, M.A. ${ }^{5}$

\begin{abstract}
RESUMO - C. bonariensis (Conyza bonariensis) é uma planta daninha da família Asteraceae, amplamente distribuida no Brasil, com presença marcante nos Estados do Rio Grande do Sul e do Paraná. Biótipos de C. bonariensis resistentes ao glyphosate foram identificados nos Estados do Rio Grande do Sul, Paraná e São Paulo. O objetivo deste trabalho foi avaliar o efeito de diferentes manejos de inverno e na pré-semeadura da soja sobre a população de plantas de $C$. bonariensis resistente ao herbicida glyphosate. Os resultados evidenciaram que a população de $C$. bonariensis é maior em áreas mantidas sem cultivo (pousio) do que naquelas áreas cultivadas com trigo ou aveia-preta durante o inverno. Observou-se que o trigo e a aveia-preta exercem efeito supressor sobre a população de C. bonariensis, proporcionando maior facilidade de controle com herbicida na pré-semeadura da cultura usada em sucessão. O controle de C. bonariensis resistente ao herbicida glyphosate foi satisfatório quando se utilizaram herbicidas pós-emergentes na cultura do trigo e glyphosate $+2,4-\mathrm{D}$ ou glyphosate + diuron + paraquat na pré-semeadura da soja.
\end{abstract}

Palavras-chave: C. bonariensis, resistência, trigo.

ABSTRACT - Horseweed (Conyza bonariensis), which belongs to the Asteraceae family, is a weed species widely spread in Brazil. Horseweed biotypes resistant to glyphosate, the main herbicide used in Roundup Ready soybean fields, were identified in the states of Rio Grande do Sul and Parana. The aim of this study was to evaluate the effect of different winter and pre-sowing management techniques on soybean plant population of $\mathbf{C}$. bonariensis resistant to glyphosate. The results showed that the population of $\boldsymbol{C}$. bonariensis is larger in areas maintained fallow than in areas planted with wheat or oats during the winter. Wheat and oats were found to exert a suppressive effect on the population of $\mathbf{C}$. bonariensis, providing greater ease of control with herbicide before seeding in the culture used in succession. The control of glyphosate-resistant C. bonariensis was satisfactory when post-emergence herbicides were used in wheat crop and glyphosate and 2, 4-D or glyphosate paraquat diuron in pre-planting soybeans.

Keywords: Horseweed, resistance, wheat.

\section{INTRODUÇÃO}

$\mathrm{Na}$ agricultura, os fatores de produção, como cultivares, fertilidade do solo, manejo de insetos, doenças e plantas daninhas, estão relacionados de tal modo que qualquer um deles pode ser limitante da produção
(Radosevich et al., 1997). Os efeitos negativos da interferência causados pelas plantas daninhas se manifestam sobre a quantidade e a qualidade da produção agrícola, em consequência da competição pelos recursos do ambiente, da alelopatia ou por serem agentes que hospedam pragas e doenças (Dias, 2004).

1 Recebido para publicação em 25.5.2010 e na forma revisada em 18.2.2011.

2 Tecnólogo em Produção de Grãos, aluna do Programa de Pós-Graduação em Fitossanidade da Universidade Federal de Pelotas UFPel, Caixa Postal 354, 96010-900 Capão do Leão-RS, <depaulajm@ibest.com.br>; ${ }^{3}$ Engo-Agrº. ${ }^{\circ}$, Dr., Pesquisador da Embrapa Trigo, Caixa Postal 451, 99001-970 Passo Fundo-RS, <vargas@cnpt.embrapa.br>; ${ }^{4}$ Professor da Faculdade de Agronomia Eliseu Maciel, UFPel, Caixa Postal 354, 96010-900 Capão do Leão-RS, <agostinetto@ig.com.br>; ${ }^{5}$ Eng $^{-}$-Agr ${ }^{0}$., Aluno do Programa de Pós-Graduação em Fitossanidade, UFPel, Caixa Postal 354, 96010-900 Capão do Leão-RS, <marcosnohatto@hotmail.com>. 
C. bonariensis é uma espécie nativa da América do Sul e ocorre na Argentina, Uruguai, Paraguai e Brasil. É uma planta anual que se reproduz por sementes que germinam no outono/inverno, com encerramento do ciclo na primavera e verão (Weaver, 2001). A espécie apresenta grande produção de sementes e fácil dispersão, caracterizando-se como agressiva (Kissmann \& Groth, 1999).

A rápida dispersão de C. bonariensis provavelmente se deve à grande produção de sementes. Uma única planta pode produzir até 150.000 sementes, que são facilmente dispersadas pelo vento (Dauer et al., 2007), indicando que essa espécie possui alta capacidade para formar banco de sementes em curto espaço de tempo.

O glyphosate é um herbicida sistêmico, não seletivo, altamente solúvel em água, e seu mecanismo de ação baseia-se na interrupção da rota do ácido chiquímico, responsável pela produção dos aminoácidos aromáticos fenilalanina, tirosina e triptofano, essenciais para a sintese de proteínas e divisão celular nas regiões meristemáticas da planta (Hess, 1994). Foi introduzido comercialmente em 1974 e atualmente é o herbicida mais usado em todo o mundo, devido principalmente a características como baixa toxicidade aos mamíferos, rápida degradação no meio ambiente e consequente mínima contaminação das águas subterrâneas e ação sistêmica e eficaz em uma diversificada flora (Baylis, 2000).

O glyphosate é utilizado em pós-emergência para manejo da cobertura vegetal anual e perene antes da semeadura das culturas, principalmente no sistema de semeadura direta (Kruse et al., 2000; Magalhães et al., 2001). Esse herbicida também pode ser utilizado em pós-emergência total, em culturas transgênicas (soja Roundup Ready ${ }^{\circledR}$ ) resistentes, e de forma dirigida em outras culturas não transgênicas, proporcionando controle de plantas daninhas durante todo o ciclo agrícola.

A introdução da soja transgênica, resistente ao glyphosate, representou grande avanço no controle das plantas daninhas. Entretanto, isso também proporcionou aumento considerável no uso do glyphosate; atualmente, realizam-se de duas a três aplicações desse herbicida por ciclo da cultura (Vargas et al., 2007).
Essa aplicação repetida de glyphosate provoca grande pressão de seleção e a possibilidade da seleção de espécies daninhas tolerantes ou resistentes (Christoffoleti \& López-Ovejero, 2003).

A ampla utilização do glyphosate no mundo resultou na seleção de biótipos resistentes a esse herbicida em vários países, inclusive no Brasil, onde já existem relatos de Lolium multiflorum, Digitaria insularis, Conyza bonariensis e C. canadensis resistentes (Christoffoleti et al., 2006; Montezuma et al., 2006; Moreira et al., 2006; Vargas et al., 2006; Lamego \& Vidal, 2008).

Depois de constatada a resistência, um dos principais problemas é desenvolver estratégias de manejo dessas plantas nas lavouras e, sobretudo, evitar a dispersão desses biótipos para outras áreas (Christoffoleti \& LopezOvejero, 2003).

Entre as medidas culturais, a utilização de cobertura do solo é uma prática que apresenta efeitos positivos na supressão de plantas daninhas (Vidal \& Trezzi, 2004; Rizzardi \& Silva, 2006).

A cobertura do solo reduz significativamente a infestação de plantas daninhas e modifica a composição da população infestante (Mateus et al., 2004). Assim, a presença de residuos de culturas (palha) atrasa e reduz a emergência de plântulas de $C$. bonariensis e C. canadensis, sendo isso comum em situações onde se pratica semeadura direta. $O$ efeito da cobertura morta no controle da comunidade infestante vem sendo atribuído à liberação de compostos alelopáticos e a efeitos fisicos (Almeida \& Rodrigues, 1985). Os efeitos fisicos da cobertura morta sobre as plantas daninhas podem ser atribuídos à filtragem da luz, alterando a quantidade e a qualidade do comprimento das ondas luminosas que chegam até as sementes das plantas daninhas e a manutenção da temperatura com menores oscilações (Fener, 2006).

Outra forma de manejar e prevenir a seleção de plantas daninhas tolerantes ou resistentes é com o uso de associações de herbicidas que apresentem mecanismos de ação distintos (Powles \& Holtum, 1994). Trabalhos conduzidos por Vargas et al. (2007) evidenciam a eficiência na utilização de herbicidas como 
o 2,4-D e metsulfuron-metílico associados ao glyphosate, além de aplicações sequenciais envolvendo a combinação de glyphosate e paraquat + diuron e glufosinato de amônio isolado para controle de C. bonariensis. O objetivo deste trabalho foi avaliar o efeito de diferentes manejos de inverno e na pré-semeadura da soja sobre população de plantas de $C$. bonariensis resistentes ao herbicida glyphosate.

\section{MATERIAL E MÉTODOS}

Foram realizados dois experimentos em campo, em área infestada com plantas de C. bonariensis resistentes ao herbicida glyphosate, no município de Cruz Alta-RS, região fisiográfica Planalto Médio, entre os meses de maio de 2007 e abril de 2008.

O primeiro experimento objetivou avaliar a eficiência do controle de $C$. bonariensis na cultura do trigo com uso de diferentes herbicidas e, posteriormente, nessa mesma área, avaliar a eficiência de diferentes tratamentos herbicidas usados no manejo da vegetação na pré-semeadura da soja. Esse ensaio foi instalado em área infestada com $C$. bonariensis resistente ao herbicida glyphosate, manejada sob sistema de semeadura direta.

Para manejo da vegetação, antes da instalação do ensaio, foi realizada dessecação, utilizando-se os herbicidas glyphosate (1.080 g e.a. ha-1) e 2,4-D (1.139 g i.a. ha ${ }^{1}$ ), com volume de calda de $200 \mathrm{~L} \mathrm{ha}^{-1}$. Duas semanas após a dessecação foi semeado o trigo (22/7/2007).

A variedade de trigo utilizada foi a BRS Timbaúva, de ciclo médio, semeada em linhas espaçadas de $0,17 \mathrm{~m}$, com densidade de 350 sementes $\mathrm{m}^{-2}$, que proporcionou população de 199 plantas $\mathrm{m}^{2}$. A adubação foi realizada na semeadura, utilizando-se $300 \mathrm{~kg} \mathrm{ha}^{-1}$ de adubo da fórmula 5-30-15 (NPK), determinada com base em análise do solo.

Na adubação em cobertura do trigo, utilizaram-se $100 \mathrm{~kg} \mathrm{ha}^{-1}$ de nitrogênio $(\mathrm{N})$, aplicado na forma de ureia, fracionada em duas aplicações de $50 \mathrm{~kg}$ ha ${ }^{-1}$ de nitrogênio: uma no início do afilhamento e outra no início do alongamento do colmo. O controle de doenças e insetos e as demais práticas de manejo foram realizados conforme indicações para a cultura do trigo.

O delineamento experimental foi de parcelas subdivididas, com três repetições; as parcelas principais apresentavam dimensões de $1,53 \times 40 \mathrm{~m}$ onde foram alocados os tratamentos herbicidas pós-emergentes aplicados na cultura do trigo (Tabela 1). Esses tratamentos foram aplicados em 1/8/2007, quando o trigo se encontrava no estádio vegetativo de pleno afilhamento.

As subparcelas, com dimensões de 1,53 x $5 \mathrm{~m}$, foram constituídas pelos tratamentos aplicados após a colheita do trigo e na pré-semeadura da soja (Tabela 2). Esses tratamentos foram aplicados em 7 de dezembro de 2007 sobre as plantas de $C$. bonariensis que estavam em estádio vegetativo, com estatura de 10 a $50 \mathrm{~cm}$ e população média de 44 plantas $\mathrm{m}^{-2}$.

A aplicação dos tratamentos foi realizada com pulverizador costal de precisão pressurizado a $\mathrm{CO}_{2}$, com barra contendo quatro bicos do tipo leque 110.015, trabalhando na pressão de $20,22 \mathrm{kPa}$ e com volume de calda de $150 \mathrm{~L} \mathrm{ha}^{-1}$.

As variáveis avaliadas na cultura do trigo foram: toxicidade à cultura do trigo, número de plantas de $C$. bonariensis e componentes de rendimento do trigo. Na pré-semeadura da soja, avaliou-se o controle de C. bonariensis pelos diferentes tratamentos herbicidas. A fitoxicidade ao trigo foi avaliada aos 7,14 e 28 dias após aplicação do tratamento (DAT). Já o número de plantas de $C$. bonariensis foi avaliado aos 112 dias após aplicação dos tratamentos herbicidas na cultura do trigo, por meio da contagem em quatro áreas de $0,25 \mathrm{~m}^{-2}$, por parcela, sendo os resultados expressos em plantas $\mathrm{m}^{-2}$.

Os componentes de rendimento foram determinados aos 152 dias após a emergência (DAE), sendo: número de antécios por espiga (NAE), grãos por espiga (NGE) e peso de mil grãos (PMG). Para isso, foram coletadas 50 espigas aleatoriamente em cada parcela.

$\mathrm{O}$ peso de mil grãos (PMG) foi determinado por meio da pesagem de cinco subamostras de cem grãos de cada parcela, e os resultados foram expressos como peso de mil grãos. Os valores foram ajustados a $13 \%$ de umidade. 
Tabela 1 - Herbicidas pós-emergentes aplicados na cultura do trigo. Cruz Alta-RS, 2007/08

\begin{tabular}{|l|c|}
\hline \multicolumn{1}{|c|}{ Ingrediente ativo } & Ingrediente ativo (g e.a $\mathrm{a}^{1}$.ou i.a. ha $\left.{ }^{-1}\right)$ \\
\hline Metsulfuron-metílico + clodinafope propargil & $2,4+36$ \\
\hline 2,4-D + clodinafope-propargil & $806+36$ \\
\hline Iodosulfuron - metílico & 5 \\
\hline
\end{tabular}

Tabela 2 - Herbicidas aplicados na dessecação pré-semeadura da soja. Cruz Alta-RS, 2007/08

\begin{tabular}{|l|c|}
\hline \multicolumn{1}{|c|}{ Ingrediente ativo } & Ingrediente ativo (g e.a. ou i.a. ha $^{-1}$ ) \\
\hline Glyphosate & 1080 \\
\hline Glyphosate + clorimurom-etílico & $1.080+24$ \\
\hline Glyphosate + clorimurom-etílico & $1.080+32$ \\
\hline Glyphosate + 2,4-D & $1.080+1.209$ \\
\hline Glyphosate + diclosulam & $1.080+35,28$ \\
\hline Glyphosate + sulfentrazona & $1.080+400$ \\
\hline Glyphosate + diuron + dicloreto de paraquat & $1.080+150+300$ \\
\hline Glyphosate + diuron + dicloreto de paraquat & $1.080+200+400$ \\
\hline
\end{tabular}

Para obtenção da produtividade $(\mathrm{P})$ do trigo, realizou-se a colheita mecânica, de forma individualizada, das parcelas; os grãos de trigo foram pesados e corrigidos a $13 \%$ de umidade e expressos em $\mathrm{kg} \mathrm{ha}^{-1}$. O controle de $C$. bonariensis proporcionado pelos tratamentos usados para manejo antes da semeadura da soja foi realizado aos 12 e 30 dias após a aplicação dos tratamentos (DAT), de forma visual, utilizando-se escala percentual (\%), em que nota zero (0) e nota cem (100) corresponderam à ausência de injúria ou morte, respectivamente.

Os dados foram avaliados quanto a sua homocedasticidade e normalidade e submetidos à analise de variância $(\mathrm{p} \leq 0,05)$. As comparações de médias foram efetuadas pelo teste de Tukey $(\mathrm{p} \leq 0,05)$.

No segundo experimento, avaliou-se o efeito de diferentes coberturas (trigo, aveia e pousio) durante o inverno sobre a população de $C$. bonariensis e o controle dessas plantas com diferentes tratamentos herbicidas usados no manejo da vegetação em pré-semeadura da soja. O delineamento utilizado foi de parcelas subdivididas; as parcelas principais, que mediam 15 × $40 \mathrm{~m}$, constaram de manejos realizados durante o inverno (trigo, aveia-preta e pousio), e nas subparcelas $(1,53$ x $5 \mathrm{~m}$ ) constaram os diferentes herbicidas e associações (Tabela 2) aplicados na pré-semeadura da soja.
O experimento foi instalado na mesma época e manejado de modo semelhante ao descrito no experimento 1 .

A semeadura do trigo e da aveia-preta ocorreu no dia 22 de junho de 2007. O trigo foi manejado de forma semelhante à do primeiro experimento, e a aveia-preta comum foi semeada em linhas espaçadas de $0,17 \mathrm{~m}$, com densidade de 400 sementes $\mathrm{m}^{-2}$, proporcionando 130 plantas $\mathrm{m}^{-2}$.

A aplicação dos tratamentos (Tabela 2) na pré-semeadura da soja foi realizada em 7 de dezembro de 2007, utilizando pulverizador costal de precisão pressurizado a $\mathrm{CO}_{2}$, com barra contendo quatro bicos do tipo leque 110.015, trabalhando na pressão de 20,22 libras pol-2, com volume de calda de $150 \mathrm{~L} \mathrm{ha}^{-1}$. Na época de aplicação, as plantas de C. bonariensis encontravam-se em estádio vegetativo, com estatura de 30 a $50 \mathrm{~cm}$. Na área cultivada com trigo, as plantas de $C$. bonariensis foram cortadas pela colhedora e, portanto, os herbicidas foram aplicados sobre caules de aproximadamente $10 \mathrm{~cm}$.

As variáveis avaliadas foram: número de plantas e estatura de C. bonariensis em cada cobertura de solo (aveia, trigo e pousio) durante o inverno e eficiência dos tratamentos herbicidas usados na dessecação pré-semeadura da soja em cada uma das coberturas. O número 
de plantas de $C$. bonariensis foi avaliado antes da aplicação dos tratamentos herbicidas em pré-semeadura da soja, por meio da contagem em quatro áreas de $0,25 \mathrm{~m}^{-2}$, por parcela, sendo os resultados expressos em plantas $\mathrm{m}^{-2}$. A estatura das plantas foi avaliada medindo-se aleatoriamente quatro plantas por parcela. As avaliações de eficiência no controle de C. bonariensis foram feitas aos 12 e 30 DAT, visualmente, utilizando-se escala percentual $(\%)$, em que a nota zero (0) e nota cem (100) corresponderam à ausência de injúria ou morte, respectivamente.

Os dados foram avaliados quanto a sua homocedasticidade e normalidade e, posteriormente, submetidos à analise de variância $(\mathrm{p} \leq 0,05)$. As comparações de médias foram efetuadas pelo teste de Tukey $(p \leq 0,05)$.

\section{RESULTADOS E DISCUSSÃO}

No primeiro experimento, os tratamentos não causaram toxicidade à cultura do trigo. Quanto ao número de plantas de C. bonariensis, observa-se menor população nas parcelas tratadas com os herbicidas do que aquela observada na testemunha. Na testemunha, observaram-se 42 plantas $\mathrm{m}^{-2}$, enquanto nos tratamentos metsulfuron-metílico + clodinafope propargil, 2,4-D + clodinafope propargil e iodosulfuron-metílico o número de plantas $\mathrm{m}^{-2}$ foi de 19,16 e 14 , respectivamente (Figura 1).

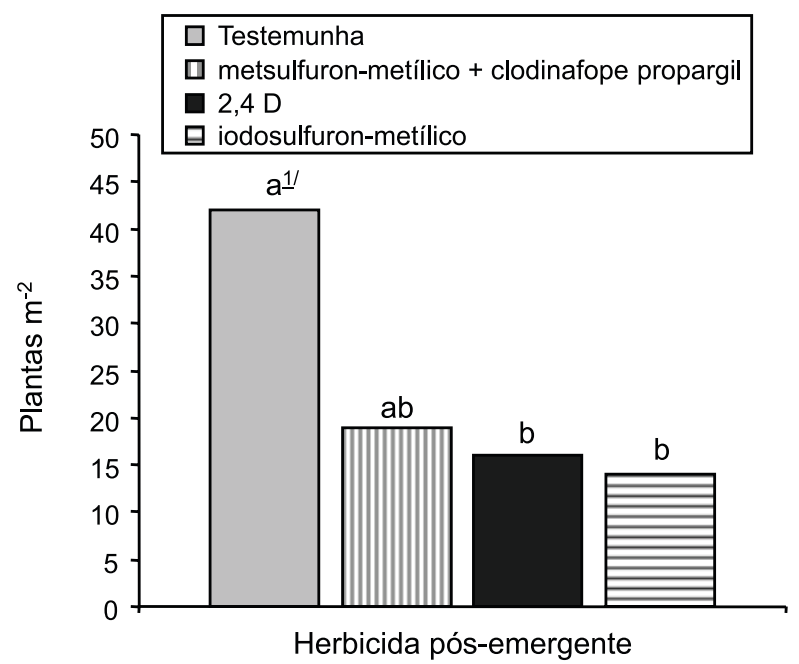

Figura 1 - Plantas $\left(\mathrm{m}^{-2}\right)$ de Conyza bonariensis, avaliadas aos 112 dias após a aplicação dos tratamentos herbicidas pósemergentes na cultura do trigo. Cruz Alta - RS, 2007.
O menor número de plantas observado nas parcelas que receberam tratamento herbicida pode ser atribuído ao controle de plantas no momento da aplicação e à ação residual dos produtos utilizados. Conforme Trezzi \& Vidal (2001), herbicidas do grupo da ALS, como o metsulfuron-metílico e iodosulfuron, podem apresentar meia-vida no solo de 30 a 120 dias. Resíduos de metsulfuron-metílico podem ocorrer mesmo em condições normais das taxas de aplicação. Ghani et al. (2001) constataram que aproximadamente $50 \%$ do herbicida metsulfuron-metílico estava presente no solo após quatro meses e meio da aplicação. Dessa forma, o uso de herbicidas na cultura do trigo reduz o número de plantas de $C$. bonariensis na área, comparativamente com o não uso desses produtos.

Nos componentes de rendimento NGE, NAE e PMG, não houve diferenças significativas entre os tratamentos (Tabela 3). Para a variável $\mathrm{P}$, observaram-se valores semelhantes entre os tratamentos herbicidas e superiores aos da testemunha, à exceção de 2,4-D + clodinafope, o qual não diferiu da testemunha. Isso evidencia, de forma geral, que os tratamentos herbicidas foram efetivos no controle de C. bonariensis e das demais plantas daninhas, refletindo em maior rendimento (Tabela 3). Apesar de não terem sido observadas diferenças entre os componentes de rendimento, constataram-se diferenças percentuais no rendimento. Isso pode ser devido a pequenas diferenças entre os componentes de rendimento $\mathrm{NGE}$, NAE, e PMG, não detectadas pelo teste estatístico aplicado, mas que, somadas, influenciam no rendimento total.

Em relação à eficiência de controle de C. bonariensis com herbicidas em pré-semeadura da cultura da soja, na primeira avaliação, realizada aos 12 DAT, observou-se maior controle no tratamento glyphosate $+2,4-\mathrm{D}$, seguido de glyphosate (1.080 g e.a. ha-1) + clorimurom-etílico (32 g i.a. ha ${ }^{-1}$ ). Os demais tratamentos apresentaram niveis de controle inferiores a $50 \%$ (Tabela 4).

$\mathrm{Na}$ segunda avaliação, aos $30 \mathrm{DAT}$, foi observada maior eficiência nos tratamentos com glyphosate $+2,4-\mathrm{D}$ e glyphosate + diclosulam, em nivel acima de $97 \%$ (Tabela 4). 
Entretanto, o controle do tratamento glyphosate + diclosulam não diferiu daquele do tratamento glyphosate $\left(1.080\right.$ g e.a. ha $\left.{ }^{-1}\right)+$ diuron (200 g i.a. ha-1) + dicloreto de paraquat (400 g i.a. ha ${ }^{-1}$ ), que proporcionou $91 \%$ de controle de $C$. bonariensis. De forma geral, observou-se maior eficiência no controle de C. bonariensis com uso de associações de herbicidas, quando comparado ao tratamento isolado do herbicida glyphosate (Tabela 4). Verificou-se que o herbicida glyphosate isolado evidenciou o menor nivel de controle nas duas avaliações (12 e 30 DAT), superando apenas o tratamento testemunha. O baixo nivel de controle do glyphosate aplicado isoladamente deve-se ao fato de as plantas dessa área serem resistentes a esse mecanismo herbicida.

Resultados semelhantes foram observados por Wu et al. (2008). Esses autores verificaram que o controle de $C$. bonariensis em área sob pousio não foi eficiente quando se utilizou apenas um herbicida. Esses autores sugerem a associação do glyphosate com herbicidas do grupo das auxinas, como o 2,4-D e dicamba, para controle eficiente de $C$. bonariensis. Eubank et al. (2008) avaliaram o controle de C. bonariensis com estatura de 15 a $30 \mathrm{~cm}$, resistente ao herbicida glyphosate, na cultura da soja e observaram que a aplicação somente de glyphosate na dose de 860 g e.a. ha ${ }^{-1}$ controla $65 \%$, e a dose de 1.250 g e.a. ha ${ }^{-1}$ controla 74\%. Já a dose de 860 g e.a. ha ${ }^{-1}$ aplicada em associação com 2,4-D (840 g e.a. ha-1), quatro semanas após o tratamento, proporciona controle de $90 \%$.

No segundo experimento, o número de plantas de $C$. bonariensis observado na área cultivada com trigo, aveia-preta e em pousio foi de 42,68 e 168 plantas $\mathrm{m}^{-2}$, respectivamente (Figura 2). Os resultados evidenciam que a cobertura de solo com cultivo de trigo ou aveia-preta reduz significativamente a

Tabela 3 - Número de grãos por espiga (NGE), número de antécios por espiga (NAE), peso de mil grãos (PMG) e produtividade (P), em função da aplicação de herbicidas pós-emergentes na cultura do trigo. Cruz Alta-RS, 2007/08

\begin{tabular}{|l|c|c|c|c|}
\hline \multirow{2}{*}{ Tratamento $\left(\mathrm{g}\right.$ i.a. $\left.\mathrm{ha}^{-1}\right)$} & \multicolumn{4}{|c|}{ Componente da produtividade } \\
\cline { 2 - 5 } & NGE & NAE & PMG $(\mathrm{g})$ & $\mathrm{P}\left(\mathrm{kg} \mathrm{ha}^{-1}\right)$ \\
\hline Testemunha & $51 \mathrm{a}^{1 /}$ & $12 \mathrm{a}$ & $24 \mathrm{a}$ & $903 \mathrm{~b}$ \\
\hline Metsulfuron-metílico + clodinafope propargil $(2,4+36)$ & $53 \mathrm{a}$ & $13 \mathrm{a}$ & $28 \mathrm{a}$ & $1.195 \mathrm{a}$ \\
\hline 2,4-D + clodinafope propargil (806+36) & $56 \mathrm{a}$ & $13 \mathrm{a}$ & $26 \mathrm{a}$ & $1.027 \mathrm{ab}$ \\
\hline Iodosulfuron-metílico (5) & $56 \mathrm{a}$ & $13 \mathrm{a}$ & $25 \mathrm{a}$ & $1.237 \mathrm{a}$ \\
\hline
\end{tabular}

1/ Médias seguidas por mesma letra, na coluna, não diferem entre si pelo teste de Tukey $(\mathrm{p} \leq 0,05)$.

Tabela 4 - Controle (\%) de Conyza bonariensis com herbicidas em pré-semeadura da cultura da soja aos 12 e 30 dias após aplicação dos tratamentos (DAT). Cruz Alta-RS, 2007/08

\begin{tabular}{|c|c|c|}
\hline \multirow{2}{*}{ Tratamento (g e.a. ou i.a. ha ${ }^{-1}$ ) } & \multicolumn{2}{|c|}{ Época de avaliação } \\
\hline & 12 DAT & 30 DAT \\
\hline Testemunha & $0 \mathrm{~g}^{1 /}$ & $0 \mathrm{~g}$ \\
\hline Glyphosate $\left(1.080\right.$ g e.a. ha $\left.{ }^{-1}\right)$ & $22 \mathrm{f}$ & $12 \mathrm{f}$ \\
\hline Glyphosate $\left(1.080\right.$ g e.a. ha $\left.^{-1}\right)+$ clorimurom-etílico $\left(24\right.$ g i.a. ha $\left.^{1}\right)$ & $39 \mathrm{~d}$ & 64 e \\
\hline Glyphosate $\left(1.080\right.$ g e.a. ha $\left.{ }^{-1}\right)+$ clorimurom-etílico $\left(32\right.$ g i.a. ha $\left.^{-1}\right)$ & $52 \mathrm{~b}$ & $78 \mathrm{~d}$ \\
\hline Glyphosate $\left(1.080\right.$ g e.a. ha $\left.{ }^{-1}\right)+2,4-D\left(1209\right.$ g i.a. ha $\left.{ }^{-1}\right)$ & $57 \mathrm{a}$ & $100 \mathrm{a}$ \\
\hline Glyphosate $\left(1.080\right.$ g e.a. ha $\left.{ }^{-1}\right)+$ diclosulam $\left(35,28\right.$ g i.a. ha $\left.{ }^{-1}\right)$ & $47 \mathrm{c}$ & $97 \mathrm{ab}$ \\
\hline Glyphosate $\left(1.080\right.$ g e.a. ha $\left.{ }^{-1}\right)+$ sulfentrazona $\left(400\right.$ g i.a. ha $\left.{ }^{-1}\right)$ & $39 \mathrm{~d}$ & $67 \mathrm{e}$ \\
\hline Glyphosate $\left(1.080\right.$ g e.a. ha $\left.{ }^{-1}\right)+$ diuron $\left(150 \mathrm{~g}_{\text {i.a. }} \mathrm{ha}^{-1}\right)+$ dicloreto de paraquat $\left(300 \mathrm{~g}\right.$ i.a. ha $\left.{ }^{-1}\right)$ & $28 \mathrm{e}$ & $86 \mathrm{c}$ \\
\hline Glyphosate $\left(1.080\right.$ g e.a. ha $\left.{ }^{-1}\right)+$ diuron $\left(200 \mathrm{~g}\right.$ i.a. ha $\left.^{-1}\right)+$ dicloreto de paraquat $\left(400 \mathrm{~g}\right.$ i.a. ha $\left.^{-1}\right)$ & 25 ef & $91 \mathrm{bc}$ \\
\hline
\end{tabular}

${ }_{1 /}$ Médias seguidas por mesma letra, na coluna, não diferem entre si pelo teste de Tukey $(p \leq 0,05)$. 
população de C. bonariensis. Verificou-se redução de $75 \%$ do número de plantas $\mathrm{m}^{-2}$ no cultivo com trigo e $60 \%$ com aveia-preta, quando comparado à área em pousio (Figura 2). Além da redução da população de plantas de C. bonariensis, o cultivo da área com trigo ou aveia-preta também afetou a estatura das plantas dessa planta daninha (Figura 3).

A avaliação de controle de C. bonariensis com herbicidas para manejo da vegetação pré-semeadura da soja nas áreas cultivadas com trigo, aveia-preta ou pousio, realizada aos 12 DAT, dentro do manejo com trigo, demonstrou que o melhor controle ocorreu com o tratamento glyphosate $+2,4-\mathrm{D}$ e no tratamento glyphosate $\left(1.080\right.$ g e.a. ha $\left.{ }^{-1}\right)+$ clorimurometílico (32 g i.a. ha ${ }^{-1}$ ) (Tabela 5).

No manejo aveia-preta, observou-se que o melhor controle ocorreu com o tratamento glyphosate +2,4-D. Já no manejo pousio o melhor controle foi obtido nos tratamentos glyphosate + 2,4-D e glyphosate + diclosulam (Tabela 5)

$\mathrm{Na}$ avaliação realizada aos $30 \mathrm{DAT}$, na área cultivada com trigo observou-se maior controle de $C$. bonariensis nos tratamentos glyphosate $+2,4-\mathrm{D}$, glyphosate + diclosulam e glyphosate + diuron + dicloreto de paraquat nas duas doses testadas (Tabela 5). Na área cultivada com aveia, os tratamentos com glyphosate $+2,4-\mathrm{D}$ e glyphosate + diuron + dicloreto de paraquat na dose maior foram os que apresentaram maior eficiência de controle. Na área mantida em pousio, o maior controle de $C$. bonariensis foi verificado para os tratamentos com glyphosate $+2,4-\mathrm{D}$ e os tratamentos de glyphosate associados com diuron e dicloreto de paraquat (Tabela 5).

Dessa forma, fica evidente o efeito do cultivo no inverno sobre a população de C. bonariensis no final do ciclo dessas culturas, o que proporciona melhor condição de manejo na pré-semeadura da cultura que virá em sucessão. Neste experimento, avaliaram-se diferentes tratamentos antes da semeadura da soja e ficou evidente que o controle ou supressão é importante, pois, além de reduzir a competição das plantas daninhas no período de estabelecimento da cultura da soja, facilita o controle pós-emergente, que pode ser realizado com maior flexibilidade de tempo e doses herbicidas.
Trabalhos de Carvalho et al. (2000) enfatizam que a estratégia de associar herbicidas no manejo pré-semeadura das culturas, para ampliar o espectro de controle do glyphosate, é amplamente utilizada há algum tempo, e o herbicida 2,4-D é um dos produtos possiveis de serem utilizados. Os resultados obtidos neste trabalho evidenciam a importância da utilização de herbicidas com diferentes mecanismos de ação como alternativa no controle de C. bonariensis resistente ao glyphosate.

Conforme Bruce \& Kells (1990), em áreas sob semeadura direta de soja, onde não se

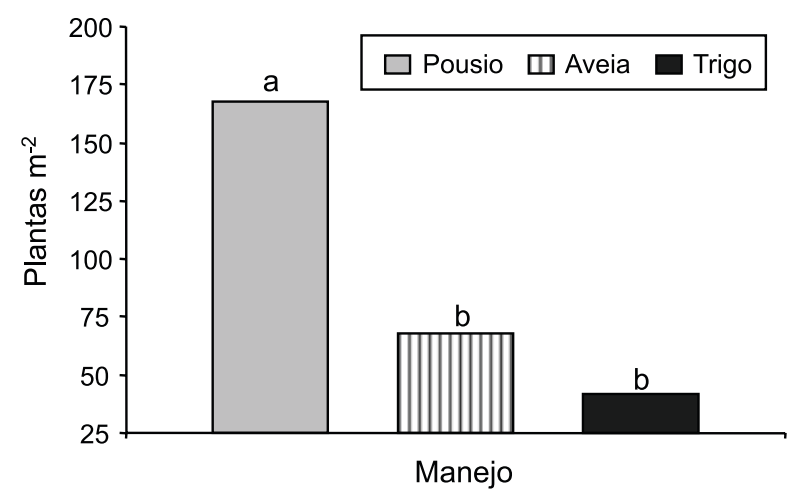

${ }^{1 /}$ Letras idênticas não diferem pelo teste de Tukey $(\mathrm{p} \leq 0,05)$.

Figura 2 - Número de plantas $\left(\mathrm{m}^{-2}\right)$ de Conyza bonariensis, avaliadas antes da aplicação dos tratamentos herbicidas em pré-semeadura da soja. Cruz Alta-RS, 2007/08.

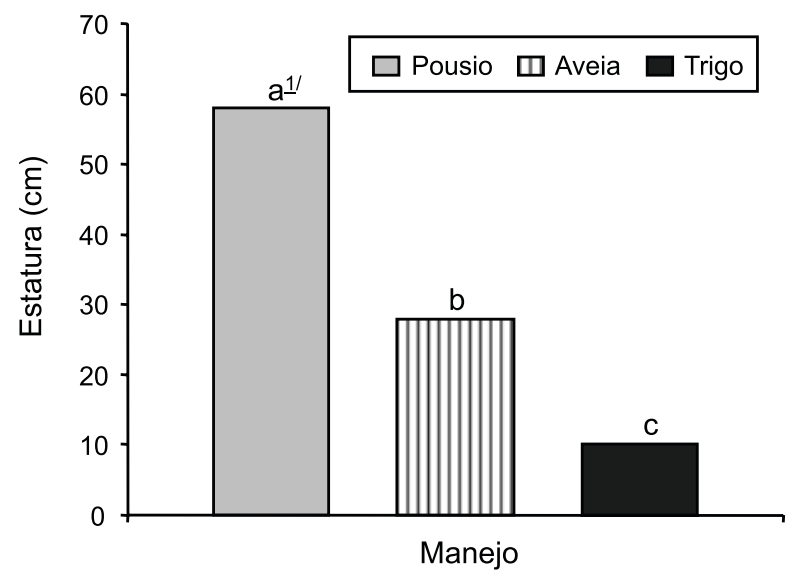

${ }^{1 /}$ Letras idênticas não diferem pelo teste de Tukey $(\mathrm{p} \leq 0,05)$.

Figura 3 - Estatura (cm) de plantas de Conyza bonariensis, avaliadas antes da aplicação dos tratamentos herbicidas em pré-semeadura da soja. Cruz Alta-RS, 2007/08.

Planta Daninha, Viçosa-MG, v. 29, n. 1, p. 217-227, 2011 
Tabela 5 - Controle (\%) de Conyza bonariensis com herbicidas em pré-semeadura da cultura da soja aos 12 e 30 DAT (dias após a aplicação dos herbicidas). Cruz Alta-RS, 2007/08

\begin{tabular}{|c|c|c|c|}
\hline \multirow{2}{*}{ Tratamento (g e.a. ou i.a. ha $^{-1}$ ) } & \multicolumn{3}{|c|}{ Manejo } \\
\hline & Trigo & Aveia & Pousio \\
\hline \multirow{2}{*}{ Testemunha } & \multicolumn{3}{|c|}{ Controle aos 12 DAT } \\
\hline & $0 \mathrm{~g}^{1 /}$ & $\mathrm{A} \quad 0 \mathrm{E}$ & $0 \mathrm{e}$ \\
\hline Glyphosate $\left(1.080\right.$ g e.a. $\left.^{-1}{ }^{-1}\right)$ & A $21 \mathrm{f}$ & A $19 \mathrm{D}$ & A $20 \mathrm{~d}$ \\
\hline Glyphosate $\left(1.080\right.$ g e.a. ha $\left.{ }^{-1}\right)+$ clorimurom - etílico $\left(24\right.$ g i.a. ha $\left.{ }^{-1}\right)$ & A 38 cde & A $32 \mathrm{Bc}$ & A $29 \mathrm{~cd}$ \\
\hline Glyphosate $\left(1.080\right.$ g e.a. ha $\left.^{-1}\right)+$ clorimurom - etílico $\left(32\right.$ g i.a. ha $\left.{ }^{-1}\right)$ & A $55 \mathrm{ab}$ & B 39 B & B $32 \mathrm{bc}$ \\
\hline Glyphosate $\left(1.080\right.$ g e.a. ha $\left.{ }^{-1}\right)+2,4-D\left(1209\right.$ g i.a. ha $\left.{ }^{-1}\right)$ & A 60 a & A $54 \mathrm{~A}$ & A 51 a \\
\hline Glyphosate $\left(1.080\right.$ g e.a. ha $\left.{ }^{-1}\right)+$ diclosulam $\left(35,28\right.$ g i.a. ha $\left.{ }^{-1}\right)$ & A 46 bc & A 41 B & A $41 \mathrm{ab}$ \\
\hline 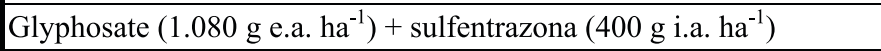 & A $39 \mathrm{~cd}$ & B $26 \mathrm{Cd}$ & B $22 \mathrm{~cd}$ \\
\hline $\begin{array}{l}\text { Glyphosate }\left(1.080 \mathrm{~g} \mathrm{e}^{\mathrm{a} .} \mathrm{ha}^{-1}\right)+\text { diuron }\left(150 \mathrm{~g} \text { i.a. } \mathrm{ha}^{-1}\right)+\text { dicloreto de } \\
\text { paraquat }\left(300 \mathrm{~g} \text { i.a. } \mathrm{ha}^{-1}\right)\end{array}$ & A $28 \mathrm{def}$ & A $24 \mathrm{Cd}$ & A $20 \mathrm{~d}$ \\
\hline $\begin{array}{l}\text { Glyphosate }\left(1.080 \mathrm{~g} \mathrm{e}^{\mathrm{a} .} \mathrm{ha}^{-1}\right)+\text { diuron }\left(200 \mathrm{~g} \text { i.a. } \mathrm{ha}^{-1}\right)+\text { dicloreto de } \\
\text { paraquat }\left(400 \mathrm{~g} \text { i.a. } \mathrm{ha}^{-1}\right)\end{array}$ & A 26 ef & A $34 \mathrm{Bc}$ & A $26 \mathrm{~cd}$ \\
\hline \multirow{2}{*}{ Testemunha } & \multicolumn{3}{|c|}{ Controle aos 30 DAT } \\
\hline & A $\quad 0 \mathrm{~d}$ & $0 \mathrm{~F}$ & A 0 e \\
\hline Glyphosate $\left(1.080{\left.\text { g e.a. } \text { ha }^{-1}\right)}\right.$ & A $13 \mathrm{~d}$ & A $11 \mathrm{~F}$ & $7 \mathrm{de}$ \\
\hline Glyphosate $\left(1.080\right.$ g e.a. ha $\left.{ }^{-1}\right)+$ clorimurom - etílico $\left(24\right.$ g i.a. ha $\left.{ }^{-1}\right)$ & A $65 \mathrm{c}$ & B $25 \mathrm{E}$ & B $19 \mathrm{~d}$ \\
\hline 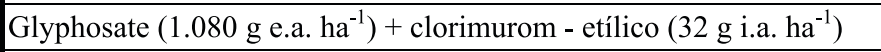 & A $78 \mathrm{bc}$ & B $54 \mathrm{D}$ & $\mathrm{C} 41 \mathrm{c}$ \\
\hline Glyphosate $\left(1.080\right.$ g e.a. ha $\left.^{-1}\right)+2,4-D\left(1209\right.$ g i.a. ha $\left.{ }^{-1}\right)$ & A 100 a & A $96 \mathrm{~A}$ & B $81 \mathrm{a}$ \\
\hline Glyphosate $\left(1.080\right.$ g e.a. ha $\left.{ }^{-1}\right)+$ diclosulam $\left(35,28\right.$ g i.a. ha $\left.{ }^{-1}\right)$ & A 98 a & B $79 \mathrm{Bc}$ & B $69 \mathrm{~b}$ \\
\hline Glyphosate $\left(1.080{\left.\text { g e.a. } \text { ha }^{-1}\right)+ \text { sulfentrazona }(400 \text { g i.a. ha }}^{-1}\right)$ & A $65 \mathrm{c}$ & B $27 \mathrm{E}$ & B $17 \mathrm{~d}$ \\
\hline 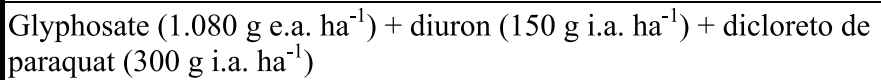 & A $87 \mathrm{ab}$ & B $71 \mathrm{C}$ & B $70 \mathrm{ab}$ \\
\hline $\begin{array}{l}\text { Glyphosate }\left(1.080 \mathrm{~g} \mathrm{e}^{\mathrm{a} .} \mathrm{ha}^{-1}\right)+\text { diuron }\left(200 \mathrm{~g} \text { i.a. } \mathrm{ha}^{-1}\right)+\text { dicloreto de } \\
\text { paraquat }\left(400 \mathrm{~g} \mathrm{i.a.} \mathrm{ha}^{-1}\right)\end{array}$ & A 93 a & A $89 \mathrm{Ab}$ & A 81 a \\
\hline
\end{tabular}

1/ Médias antecedidas por mesma letra maiúscula, nas linhas, ou seguidas por mesma letra minúscula, nas colunas, não diferem entre si pelo teste de Tukey $(\mathrm{p} \leq 0,05)$

realiza cultivo durante o inverno ou as culturas são colhidas antecipadamente, ocorre intensa infestação de $C$. bonariensis, requerendo controle antes do estabelecimento das culturas de verão. A associação de herbicidas dessecantes com efeito residual é comum entre os agricultores no manejo das áreas sob semeadura direta. Essa prática permite a dessecação da cultura de inverno a ser utilizada como cobertura morta e, também, evita a reinfestação por plantas daninhas na cultura de verão durante parte de seu ciclo (Nunes \& Vidal, 2008).

$\mathrm{Na}$ avaliação dentro de manejos, considerando as duas épocas de avaliação (12 e 30 DAT), observou-se maior eficiência dos tratamentos glyphosate $+2,4-\mathrm{D}$ e glyphosate
+ diuron (200 g i.a. ha-1) + dicloreto de paraquat (400 g i.a. ha ${ }^{-1}$ ), nos três manejos de inverno (Tabela 5). Quando a cultura antecessora foi trigo, em geral, os herbicidas usados para manejo da vegetação em pré-semeadura da soja apresentaram maior eficiência de controle. Isso pode decorrer dos efeitos físicos ou alelopáticos da cultura sobre a planta daninha, fazendo com que essas espécies apresentem características mais favoráveis ao controle.

A análise evidencia que o tratamento glyphosate $\left(1.080 \mathrm{~g}\right.$ e.a. ha $\left.{ }^{-1}\right)+$ diuron (200 g i.a. ha $\left.\mathrm{h}^{-1}\right)$ + dicloreto de paraquat (400 g i.a. ha $\mathrm{ha}^{-1}$ ) controla C. bonariensis de forma semelhante nos três sistemas de manejo avaliados aos 30 DAT, indicando que a 
ação desse tratamento não foi beneficiada pelo sistema de manejo da área, ou seja, esse tratamento superou a adversidade evidenciada no manejo pousio. O tratamento glyphosate + 2,4-D apresenta maior controle nos manejos de trigo e aveia-preta, comparativamente às áreas manejadas com pousio (Tabela 5).

Constantin \& Oliveira Jr. (2005) relatam que aplicações sequenciais de glyphosate ou 2,4-D e, após 15 a 20 dias (na véspera ou na data da semeadura da soja), aplicação de herbicidas de contato, como paraquat, paraquat + diuron, diquat ou flumioxazin, proporcionam maior eficiência no controle das plantas daninhas e permitem a semeadura no limpo.

A presença da palha pode interferir na emergência de plântulas de $C$. bonariensis e, consequentemente, no banco de sementes dessa espécie. Considerando que as sementes de Conyza spp. necessitam de luz para germinar, é provável que a presença de plantas possa impedir a germinação das sementes de C. bonariensis. Segundo Lazaroto et al. (2008), essa prática, além de impedir, também retarda a germinação, proporcionando tempo para o estabelecimento da cultura e suprimindo a germinação tardia de sementes de plantas daninhas.

No final do ciclo das culturas de inverno, a palhada remanescente pode impedir a germinação de plantas daninhas na cultura da soja. A palhada da aveia-preta, após a dessecação, é mais persistente ao longo do tempo, controlando as plantas daninhas, quando comparada a outras coberturas, como, por exemplo, nabo forrageiro (Rizzardi \& Silva, 2006). Já Theisen \& Vidal (1999) e Theisen et al. (2000) constataram que niveis crescentes de cobertura do solo com resíduos de aveia-preta reduziram a população de Brachiaria plantaginea, enquanto Oliveira et al. (2001) estimaram que, para cada tonelada de palha de milho adicionada à superficie do solo, aumentava-se em 4\% o controle das plantas daninhas.

É notável que as culturas apresentem efeito supressor sobre as plantas daninhas. Essa supressão ocorre durante a fase de desenvolvimento vegetativo das plantas envolvidas, e as interações são principalmente pela competição pelos recursos do ambiente e pela liberação de substâncias alelopáticas que afetam o crescimento das plantas daninhas (Teasdale \& Mohler, 1993).

Os resultados permitem concluir que a população de $C$. bonariensis é maior em áreas mantidas sem cultivo (pousio) do que em áreas cultivadas com trigo ou aveia-preta durante o inverno. As culturas de trigo e aveia-preta exercem efeito supressor sobre a população de $C$. bonariensis e proporcionam maior facilidade aos herbicidas para controlar as plantas dessa espécie na pré-semeadura das culturas sucessivas, por proporcionarem plantas daninhas em menor número e estatura e, assim, mais sensiveis aos herbicidas. $O$ controle de $C$. bonariensis resistente ao herbicida glyphosate foi satisfatório quando utilizados os tratamentos com herbicidas pós-emergentes da cultura do trigo e tratamentos de glyphosate+ $2,4 \mathrm{D}$ ou os tratamentos glyphosate $+2,4-\mathrm{D}$ ou glyphosate + diuron + paraquat na présemeadura da soja.

\section{AGRADECIMENTOS}

À Coordenação de Aperfeiçoamento de Pessoal de Nivel Superior (CAPES), pela concessão da bolsa de estudo ao primeiro autor.

\section{LITERATURA CITADA}

ALMEIDA, F. S.; RODRIGUES, B. N. Guia de herbicidas. Londrina: IAPAR/Livroceres, 1985. 468 p.

BAYLIS, A. D. Why glyphosate is a global herbicide: strengths, weaknesses and prospects. Pest Manag. Sci., v. 56, n. 4, p. 299-308, 2000 .

BRUCE, J. A.; KELLS, J. J. Horseweed (Conyza canadensis) control in no-tillage soybeans (Glycine max) with preplant and pre emergence herbicides. Weed Technol., v. 3, n. 4, p. 642-647, 1990.

CARVALHO, A. M.; SODRÉ FILHO, J. Uso de adubos verdes como cobertura do solo. Planaltina: Embrapa/CPAC, 2000. 20 p. (Boletim de Pesquisa, 11)

CHRISTOFFOLETI, P. J.; LOPEZ-OVEJERO, R. Principais aspectos da resistência de plantas daninhas ao herbicida glyphosate. Planta Daninha, v. 21, n. 3, p. $507-515,2003$.

Planta Daninha, Viçosa-MG, v. 29, n. 1, p. 217-227, 2011 
CHRISTOFFOLETI, P. J. et al. Herbicidas alternativos para o controle de biótipos de C. bonariensis (C. bonariensis e C. canadensis) supostamente resistentes ao herbicida glyphosate. In: CONGRESSO BRASILEIRO DE CIÊNCIA DAS PLANTAS DANINHAS, 25., 2006, Brasília.

Resumos... Londrina: SBCPD, 2006. p. 553.

CONSTANTIN, J.; OLIVEIRA Jr., R. S. Dessecação antecedendo a semeadura direta pode afetar a produtividade. Inf. Agron., n. 109, p. 14-15, 2005.

DAUER, J. T.; MORTENSEN, D. A.; VANGESSEL, M. J. Temporal and spatial dynamics of long-distance Conyza Canadensis seed dispersal. J. Applied Ecol., v. 44, n. 1, p. 105-114, 2007.

DIAS, N. M. P. Tolerância de espécies de capim-colchão (Digitaria spp) a herbicidas na cultura de cana-de-açúcar, Brasil. 2004. 118 f. Tese (Doutorado em Agronomia) Escola Superior de Agricultura Luiz de Queiroz, Universidade de São Paulo, Piracicaba, 2004

EUBANK, T. W. et al. Glyphosate-resistant horseweed (Conyza canadensis) control using glyphosate, paraquat, and glufosinate-based herbicide programs. Weed Technol., v. 22, n. 1, p. 16-21, 2008

FENNER, M. Relationships between seed weight, ash content and seedling growth in twenty-four species of Compositae. New Phytol., v. 95, n. 4, p. 697-706, 2006

GHANI, A.; WARDLE, D. A. Fate of ${ }^{14} \mathrm{C}$ from glucose and the herbicide metsulfuron-methyl in a plant-soil microcosm system soil. Biol. Biochem., v. 33, n. 6, p. 777-785, 2001.

HESS, F. D. Mechanism of action of inhibitors of amino acid biosynthesis. In: Herbicide action: an intensive course on the activity, selectivity, behavior, and fate of herbicides in plants and soil. West Lafayette: Purdue University, 1994. p. $344-365$

KISSMANN, K. G.; GROTH, D. Plantas infestantes e nocivas. São Paulo: Basf Brasileira, 1999. 789 p.

KRUSE, N. D.; TREZZI, M. M.; VIDAL, R. A. Herbicidas inibidores da EPSPs: revisão de literatura. R. Bras. Herbic., v. 2 , n. 1 , p. $139-146,2000$

LAMEGO, F. P.; VIDAL, R. A. Resistência ao glyphosate em biótipos de Conyza bonariensis e Conyza canadensis no Estado do Rio Grande do Sul, Brasil. Planta Daninha, v. 26, n. 2, p. 467-471, 2008.

LAZAROTO, C. A.; FLECK, N. G.; VIDAL, R. A. Biologia e ecofisiologia de C. bonariensis (Conyza bonariensis e Conyza canadensis). Ci. Rural, v. 38, n. 3, p. 852-860, 2008

MAGALHAES, P. C. et al. Efeito de doses reduzidas de ghyphosate e paraquat simulando deriva na cultura do sorgo. Planta Daninha, v. 19, n. 2, p. 255-262, 2001.
MATEUS, G. P.; CRUSCIOL, C. A. C.; NEGRISOLI, E. Palhada do sorgo de guiné gigante no estabelecimento de plantas daninhas em área de plantio direto. Pesq. Agropec. Bras., v. 39, n.6, p. 539-542, 2004.

MONTEZUMA, M. C. et al. Avaliação da suspeita de C. bonariensis (C. bonariensis e C. canadensis) ao herbicida glyphosate em pomares de citros no estado de São Paulo. In CONGRESSO BRASILEIRO DE CIÊNCIA DAS PLANTAS DANINHAS, 25., 2006, Brasília. Resumos... Londrina: Sociedade Brasileira da Ciência das Plantas Daninhas, 2006. p. 564 .

MOREIRA, M. S. et al. Resistência de Conyza canadensis ao herbicida glyphosate em pomares de citros no Estado de São Paulo In: CONGRESSO BRASILEIRO DE CIÊNCIA DAS PLANTAS DANINHAS, 25., 2006, Brasília. Resumos... Londrina: Sociedade Brasileira da Ciência das Plantas Daninhas, 2006. p. 554-555.

NUNES, A. L.; VIDAL, R. A. Persistência do herbicida S-metolachlor associado ao glyphosate ou paraquat em plantio direto. Planta Daninha, v. 26, n. 2, p. 385-393, 2008.

OLIVEIRA, M. F. de; ALVARENGA, R.C.; OLIVEIRA, A. C. de; CRUZ, J.C. Efeito da palha e da mistura atrazine e metolachlor no controle de plantas daninhas na cultura de milho, em sistema de plantio direto. Pesq. Agropec. Bras., v. 36, n. 1, p. $37-41,2001$

POWLES, S. B.; HOLTUM, J. A. M. Herbicide resistance in plants: biology and biochemistry. Boca Raton: CRC Press, 1994. $353 \mathrm{p}$.

RADOSEVICH, S.; HOLT, J.; GHERSA, C. Weed ecology 2.ed. New York: Wiley, 1997. 588 p.

RIZZARDI, M. A.; SILVA, L. F. Influência de coberturas vegetais antecessoras de aveia-preta e nabo forrageiro na época de controle de plantas daninhas em milho.

Planta Daninha, v. 24, n. 4, p. 621-628, 2006

TEASDALE, J. R.; MOHLER, C. L. Light transmittance, soil temperature, and soil moisture under residue of hairy vetch and rye. Agron. J., v. 85, n. 3, p. 673-680, 1993.

THEISEN, G; VIDAL, R. A. Efeito da cobertura do solo com resíduos de aveia preta nas etapas do ciclo de vida do capim-marmelada. Planta Daninha, v. 17, n. 2, p. 189-196, 1999.

THEISEN, G.; VIDAL, R. A.; FLECK, N. G. Redução da infestação de Brachiaria plantaginea em soja pela cobertura do solo com palha de aveia preta. Pesq. Agropec. Bras., v. 35, n. 4, p. 753-756, 2000. 
TREZZI, M. M.; VIDAL, R. A. Herbicidas inibidores da ALS. In: VIDAL, R. A.; TREZZI, M. M. Herbicidologia Porto Alegre: Evangraf, 2001. p. 25-36.

VARGAS, L. et al. Resistência de Conyza bonariensis ao herbicida glyphosate. In: CONGRESSO BRASILEIRO DE CIÊNCIA DAS PLANTAS DANINHAS, 25., 2006, Brasília Resumos... Londrina: Sociedade Brasileira da Ciência das Plantas Daninhas, 2006. p. 540.

VARGAS, L. et al. Conyza bonariensis resistente ao glyphosate na Região Sul do Brasil. Planta Daninha, v. 25, n. 3, p. 573-578, 2007.
VIDAL, R. A.; TREZZI, M. M. Potencial da utilização de coberturas vegetais de sorgo e milheto na supressão de plantas daninhas em condição de campo: I - Plantas em desenvolvimento vegetativo. Planta Daninha, v. 22, n. 2, p. 217-223, 2004.

WEAVER, S. E. The biology of Canadian weeds. 115. Conyza canadensis. Canadian J. Plant Sci., v. 81, n. 1, p. 867-875, 2001.

WU, H.; WALKER, S.; ROBINSON, G. Chemical control of flaxleaf fleabane (Conyza bonariensis (L.) Cronquist) in winter fallows. Plant Protec. Quarterly, v. 23, n. 4, p. 162-165, 2008. 